\title{
ARTICULANDO DISCURSO COM TRABALHO: REFLEXÕES BAKHTINIANAS E VIGOTSKIANAS DA CANÇÃO "CONSTRUÇÃO"
}

\section{ARTICULATING DISCOURSE AND WORK: BAKHTINIAN AND VYGOTSKIAN THOUGHTS ON THE “CONSTRUCTION” SONG}

\section{RESUMO}

Mariana Aguiar Alcântara de Brito ${ }^{1}$ Veriana de Fátima Rodrigues Colaço ${ }^{2}$ Cássio Adriano Braz de Aquino ${ }^{3}$

Este artigo pretendeu discutir as categorias discurso e trabalho através da canção "Construção", de autoria de Chico Buarque de Hollanda, partindo das contribuições do circulo dialógico de Bakhtin e do arcabouço da concepção materialista histórico dialética, representados aqui por autores da psicologia, como Vygotsky e Clot. A canção analisada faz parte de um contexto sócio histórico da realidade brasileira caracterizada pela ditadura militar e pela forte censura. A canção é emblemática da vertente crítica das composições do autor, configurando-se como um testemunho doloroso das relações aviltantes entre o capital e o trabalho. Contribuições acerca da noção de sujeito, do social como constitutivo do humano e de sentidos foram discutidas a luz dos referenciais citados. A análise da canção "Construção" apontou caminhos interventivos na emergência de um discurso crítico capaz de reverberar em poder de agir.

PALAVRAS-CHAVE: Análise de discurso; Psicologia do Trabalho; Chico Buarque.

\begin{abstract}
This paper aimed to discuss the speech and work categories through the song "Construção" written by Chico Buarque, based on contributions of Bakhtin's dialogical circle and the framework of the dialectical and historical materialist conception, represented here by psychology authors such as Vygotsky and Clot. The song analyzed is part of a socio-historical context of Brazilian reality characterized by the military dictatorship and the strong censorship. The song is emblematic of the critical aspects of author's compositions, configuring itself as a painful testimony of degrading relations between capital and labor. Contributions about the notion of subject, social as constitutive of a human being and senses were discussed in light of the cited references. The analysis of the song "Construção" has pointed interventional paths in the emergence of a critical discourse able to reverberate in living labor.
\end{abstract}

KEYWORDS: Discourse analysis; Psychology of Work; Chico Buarque.

\section{INTRODUÇÃO}

Discurso e trabalho são categorias sociais e históricas por excelência e, como tal, devem ser consideradas em suas dimensões processuais, explicativas e transformacionais da realidade: “A prática discursiva é prática de sujeitos que só se constituem enquanto tal porque vivem em sociedade; portanto, o primado da prática é também primado do interdiscurso" (COSTA, 2005, p. 45).

\footnotetext{
${ }^{1}$ Universidade de Fortaleza-UNIFOR, Centro Universitário 7 de Setembro, Doutoranda em psicologia pela Universidade Federal do Ceará - UFC - marianapsiorg@gmail.com.

${ }^{2}$ Professora Doutora do Departamento de Psicologia e dos Programas de Pós-Graduação em Psicologia e do Programa de Pós-Graduação em Educação da Universidade Federal do Ceará - UFC - verianac@ gmail.com.

${ }^{3}$ Professor do Departamento de Psicologia e do Programa de Pós-Graduação em Psicologia da Universidade
} Federal do Ceará - UFC

Revista Labor Fortaleza/CE, jan/jun 2017 Vol. 01, nº 17, p. 158-171 ISSN 1983-5000 
A categoria trabalho também é caracterizada pela polissemia e por sua perenidade, configurando-se, como a atividade-mor do processo de humanização do sujeito (ENGELS, 2005). No entanto, frente às demandas do capital, tem se tornado cada vez mais, restrito ao reino da necessidade do que possibilidade de liberdade e realização (MARX, 1971; ANTUNES, 2010).

A proposta deste artigo é articular discurso e trabalho através da canção "Construção", de autoria de Chico Buarque de Hollanda, partindo das contribuições do circulo dialógico de Bakhtin e do arcabouço da concepção materialista histórico dialética, representados aqui por autores da psicologia como Vygotsky e Clot.

No que compete ao método de análise configura-se como histórico-genético com foco no desenvolvimento da atividade discursiva e laboral, desde ás origens do comportamento fossilizado até a situação atual (VYGOTSKY, 2007).

A relação entre sujeito-objeto de pesquisa deve ser compreendida como uma relação dialógica, que leve em consideração a atividade do objeto pesquisado, mesmo quando composto de um produto cultural, é necessário fazer falar às vozes que habitam no objeto (COSTA, 2007).

Assim, é sob uma concepção polifônica da relação sujeito-objeto nas Ciências Humanas que será apresentada a análise de discurso da canção "Construção". "A canção popular é um objeto polifônico", tanto por ser uma produção cultural como por ser uma metáfora do discurso (COSTA, 2007, p. 25). Neste sentido, justifica-se a escolha por uma canção da música popular brasileira - MBP, capaz de trazer uma multiplicidade de gestos enunciativos, visto representar sobremaneira a cultura e a subjetividade de um povo e do próprio pesquisador aí implicado.

Sobre essa falta de neutralidade do pesquisador, o caminho percorrido é o do estranhamento que evoque um sentimento de perplexidade e de interrogação acerca do objeto pesquisado, mesmo que este também lhe seja familiar e a constituição de um dispositivo teórico que possa efetuar o desvio necessário para uma análise crítica do discurso (COSTA, 2007).

Para isso, será apresentada a seguir, uma breve contextualização sócio histórica da canção "Construção", seguida da caracterização da atividade laboral do operário do segmento de construção civil com ênfase em seus aspectos de precariedade e de significação do trabalho e uma análise do discurso da canção "Construção" com destaque para as categorias sujeito, 
social e produção de sentidos em suas articulações entre discurso e trabalho a luz das perspectivas dialéticas e dialógicas.

\section{CONTEXTUALIZAÇÃO DA CANÇÃO “CONSTRUÇÃO”: QUE PAÍ́S É ESSE?}

A canção "Construção", de autoria de Chico Buarque de Hollanda, foi composta em períodos do exílio do compositor na Itália e do seu retorno ao Brasil, sendo lançada em 1971 em formato de LP e em 1988 em forma de CD, servindo como título ao disco que também é composto por canções, como: "Deus lhe pague", "Cotidiano", "Samba de Orly", dentre outras (FERNANDES, 2004).

A canção "Construção" é emblemática da vertente crítica das composições do autor, configurando-se como um testemunho doloroso das relações aviltantes entre o capital e o trabalho.

O contexto sociopolítico brasileiro da época caracterizava-se pela ditadura militar e pela repressora censura praticada principalmente com os artistas, dos quais Chico Buarque de Hollanda era um dos mais perseguidos. Além disso, a estrutura da organização social brasileira refletia as desigualdades econômicas, sociais e políticas, e as canções críticas propunham uma reflexão sobre a condição de alienação às condições sociais vigentes (FERNANDES, 2004).

É digno de nota, também, que o país passava por um processo de expansão industrial, o que certamente impulsionou o segmento da construção civil e, por conseguinte, o aumento no número de operários neste setor da economia que permanece sendo conhecido como o menos qualificado dos segmentos econômicos (DRUCK, 2016). O discurso de Chico Buarque de Hollanda ganhou grande proporção, pois, de alguma forma, os cidadãos se identificavam prontamente com o sujeito da canção (KOGAWA, 2007).

O disco "Construção" teve grande sucesso comercial, sendo considerado um marco na carreira do cantor. Na década de 2000, o disco foi eleito um dos três melhores discos brasileiros de todos os tempos e também está citado no livro 1001 discos para ouvir antes de morrer feito por jornalistas e críticos especializados e reconhecidos internacionalmente (FERNANDES, 2004).

Neste período, Chico Buarque de Hollanda já era reconhecido como um símbolo de resistência à ditadura e se valia de uma "linguagem da fresta", expressão criada por 
Caetano Veloso que significava um modo de saber dizer e ao mesmo tempo "ludibriar o cerco do censor" (FERNANDES, 2004, p. 37).

\section{ERGUENDO PAREDES SÓLIDAS: ARTICULAÇÕES ENTRE DISCURSO E TRABALHO}

O discurso apresentado na canção "Construção” conta a estória de um operário indeterminado que trabalhou arduamente até sofrer um acidente de trabalho e então morrer. $\mathrm{O}$ discurso apresentado longe de referir-se a situações idealizadas ou extremas retrata uma materialidade concreta vivida no cotidiano das construções.

A construção civil é líder na produção de acidentes de trabalho e na negligência com as normas de segurança, configurando-se como um dos segmentos que mais faz uso do trabalho precarizado. Essa área é destaque também em acidentes fatais e na contratação de trabalhadores com baixa qualificação, apresentando altas taxas de rotatividade (DRUCK, 2016).

O ramo da construção civil é responsável por aproximadamente $25 \%$ dos casos de acidentes de trabalho no Brasil. Os fatores responsáveis por esse fato são vários, mais dois deles ganham destaque; a transitoriedade da produção na construção civil, que trabalha de forma sazonal, o que é utilizado como desculpa para as improvisações no canteiro de obra e o perfil dos trabalhadores, geralmente, oriundos da zona rural, com baixa escolaridade e qualificação (BORSOI, 2010).

Aliado a isso, soma-se a alta rotatividade e também as terceirizações e subcontratações de mão-de obra o que serve de justificativa para o pouco investimento em treinamento, e por sua vez, favorece os acidentes, doenças e mesmo a morte no contexto do trabalho, trazendo por outro lado, as portas abertas para novos profissionais, o que dinamiza o exercito de reserva fundamental para a primazia do capital (DRUCK, 2016)

Em pesquisa realizada com operários afastados por ocasião de acidentes, o tema significado do trabalho na construção foi apresentado como pesado, arriscado e como pouco compensador em termos financeiros, no entanto, paradoxalmente, o trabalho também foi visto como bom, alegre, divertido (BORSOI, 2010).

Para compreender melhor esses paradoxos, é necessário situar esta atividade laboral. Em relação à organização do trabalho, esta reproduz a lógica do trabalho rural determinado por ciclos naturais que delimitam tipo de trabalho e prazos. No tocante ao 
processo de trabalho, este é bastante artesanal e à medida que o trabalhador vai se especializando pode deter o controle sobre o processo de trabalho e constituir uma profissão.

No entanto, esse controle não é visto em relação às condições de realização do trabalho, que em geral, se dão de forma precária, sobre área descoberta, exposta a chuva e ao sol, tarefas realizadas em grandes alturas, manuseio de objetos pesados, exposição por longo tempo, a produtos nocivos á saúde, dentre outras.

O trabalho pesado, cansativo e arriscado é coerente com todo o cenário acima apresentado e o sentido de divertido e alegre foi apontado como consequência da sociabilidade construída nos canteiros de obra, frente às diferenças do processo produtivo encontrados nas fábricas com seu controle cerrado de tempo e movimento e o ritmo negociado do saber-fazer desenvolvido no trabalho da construção. Contudo essa socialização também é tida como precária frente às constantes mudanças de local de trabalho e de companheiros, apontando para a transitoriedade dos vínculos sociais e laborais (BORSOI, 2010).

Outro fator de destaque no campo de produção de sentidos do trabalho, diz respeito à afirmação da virilidade na construção civil, que pode ser representada como uma expressão da força e da coragem. Este dispositivo é frequentemente usado por gestores que utilizam esse recurso para conseguir a realização do trabalho de qualquer jeito e a qualquer tempo sob pena de desmoralizar o operário. O que ecoa entre os pares e também internamente, transformando-se em uma cobrança latente. A atitude da fuga ou da negação do trabalho é vista como ato de covardia e de falta de virilidade (DEJOURS, 2006). O uso de álcool como estratégia de defesa usada pelos operários deste segmento é destacado tanto na canção quanto nas causas dos acidentes e mortes relacionados a essa atividade (DRUCK, 2016).

A concepção dialógica de Bakhtin pode colaborar na compreensão do processo de desenvolvimento da atividade laboral e de seus impedimentos visto que a noção de humanização se dá através do trabalho enquanto atividade mediada e mediatizante. Esta interação é constituída, dentre outras, "pelas relações entre diálogo interior e o diálogo exterior" (CLOT, 2010b, p.177).

Esta dialogia é dinamizada e posta em prática nas interações laborais através das relações entre os múltiplos enunciados repletos de significados da língua, de ideologias e visões de mundo que são operacionalizados nos discursos prescritos e informais (BAKHTIN, 2000). 
O enunciado quando considerado isoladamente pode ser compreendido como individual, mas quando aparece em uma determinada esfera de utilização da língua, elabora tipos relativamente estáveis de enunciados, passando a ser denominado de gêneros do discurso. Os estilos de discurso são indissoluvelmente ligados ao enunciado e a formas típicas de enunciar, isto é, aos gêneros do discurso. (BAKHTIN, 2000).

No campo de uma categoria profissional há a emergência de um diálogo transpessoal, que se aproxima dessa concepção de gênero do discurso, e contém um vasto repertório de saberes e práticas capazes de confrontar-se com o trabalho prescrito e fossilizado do cotidiano mecanizado das organizações.

Este diálogo, longe de ser algo de fácil acolhimento, é algo que nos impacta. Longe de ser um ato deliberado de abertura ao outro, resulta da "impossibilidade de se fechar a alteridade", pois há sempre algo a ser dito (CLOT, 2010b, p.180).

$\mathrm{Na}$ atividade de trabalho, a confrontação entre os pares conforme proposição da clínica da atividade criada por Clot (2006, 2007, 2010a) serve como dispositivo dialógico capaz de fortalecer o coletivo do trabalho e ampliar seu poder de agir. Para isso, o autor propõe a análise do gênero e do estilo profissional que através do método da autoconfrontação simples e cruzada solicita "um contato de si consigo-para além de si mesmo" seguindo a inspiração bakhtiniana (CLOT, 2010b, p. 191).

O gênero representa a memória social do trabalho e está relacionado à préatividade, pois se trata de uma espécie de senha para saber como agir em determinada situação (CLOT, 2010a, LIMA, 2007). Quanto mais socializado e pertencente a um coletivo profissional e reflexivo sobre sua prática laboral, maior a chance do trabalhador, usufruir de estratégias de defesas coletivas e de meios de enfrentar as precariedades da profissão. Por outro lado, quanto maior o isolamento, o sentimento de culpa pelos erros cometidos e a mecanização do trabalho, maior a vulnerabilidade do operário.

Esse estoque de possibilidades de ação, conhecido apenas por aqueles que compartilham uma mesma situação de trabalho, gera o estilo da atividade, que representa a transformação do gênero no momento de agir em função das circunstâncias. Enquanto o gênero for renovado pelo estilo há possibilidade de uma vivência de saúde no âmbito laboral. “Quando há degenerescência do gênero há degenerescência da atividade, o que pode favorecer o desenvolvimento de patologias e também a ocorrência de acidentes no trabalho" (LIMA, 2007, p. 107). 


\section{CONSTRUÇÕES, DESCONSTRUÇÕES, RECONSTRUÇÕES: UMA ANÁLISE}

A canção popular no Brasil tem o poder de intervir na subjetividade das pessoas tanto quanto o fenômeno das telenovelas. A canção, além de polifônica, "é um gênero multissemiótico" (COSTA, 2007, p. 25), composto por melodia, letra e uma multiplicidade de gestos enunciativos que ela evoca.

A canção "Construção" faz parte do discurso constituinte brasileiro e está inserida no movimento intitulado música popular brasileira - MPB, caracterizada como um tipo de canção urbana, geralmente consumida pela população da classe média, com intenção de fortalecer a identidade nacional sem necessariamente ser ufanista (COSTA, 2004).

Segue a letra de "Construção" de Chico Buarque de Hollanda (1971), para análise:

Amou daquela vez como se fosse a última Beijou sua mulher como se fosse a última E cada filho seu como se fosse o único E atravessou a rua com seu passo tímido Subiu a construção como se fosse máquina Ergueu no patamar quatro paredes sólidas Tijolo com tijolo num desenho mágico Seus olhos embotados de cimento e lágrima Sentou pra descansar como se fosse sábado Comeu feijão com arroz como se fosse um príncipe Bebeu e soluçou como se fosse um náufrago Dançou e gargalhou como se ouvisse música E tropeçou no céu como se fosse um bêbado E flutuou no ar como se fosse um pássaro E se acabou no chão feito um pacote flácido Agonizou no meio do passeio público Morreu na contramão atrapalhando o tráfego

Amou daquela vez como se fosse o último Beijou sua mulher como se fosse a única E cada filho seu como se fosse o pródigo E atravessou a rua com seu passo bêbado Subiu a construção como se fosse sólido Ergueu no patamar quatro paredes mágicas Tijolo com tijolo num desenho lógico Seus olhos embotados de cimento e tráfego Sentou pra descansar como se fosse um príncipe Comeu feijão com arroz como se fosse o máximo Bebeu e soluçou como se fosse máquina Dançou e gargalhou como se fosse o próximo E tropeçou no céu como se ouvisse música E flutuou no ar como se fosse sábado E se acabou no chão feito um pacote tímido Agonizou no meio do passeio náufrago Morreu na contramão atrapalhando o público

Amou daquela vez como se fosse máquina Beijou sua mulher como se fosse lógico 
Ergueu no patamar quatro paredes flácidas

Sentou pra descansar como se fosse um pássaro

E flutuou no ar como se fosse um príncipe

E se acabou no chão feito um pacote bêbado

Morreu na contramão atrapalhando o sábado.

A letra de "Construção" é considerada um dos textos mais rigorosos de Chico Buarque de Hollanda, no que tange ao rigor formal e apuro técnico. Ganha destaque sua força poética permutacional, que consiste no jogo de intercambiar de forma aleatória as palavras finais, proparoxítonas, de todos os versos (CHAMIE, 2004).

O texto sugere um processo de repetição em relação às ações executadas na vida $\mathrm{e}$ no trabalho de um operário do segmento de construção, denunciando uma mecanização do corpo e da vida.

O sujeito operário é oculto enfatizando sua despersonalização, o que ocorre também com os outros personagens como a mulher que pode ser a última ou a única e os filhos que podem ser o único ou o pródigo. Representando qualquer operário da construção.

A noção de sujeito para o materialismo histórico dialético é de ser ativo, histórico e social, transformador de sua realidade e atribuidor de sentidos a partir da análise das contradições que vai se deparando em seu processo de desenvolvimento. A alienação e a tomada de consciência se alternam nessa construção (VYGOTSKY, 1996).

No dialogismo de Bakhtin, o humano é visto como um agregado de relações sociais, a presença de uma alteridade é sentida a todo o momento, especialmente através da linguagem (BARROS, 2012b).

A comparação do pedreiro com um príncipe aponta para a luta de classes inerente ao sistema e produz uma crítica social trazendo como protagonista um elemento do proletariado, seus olhos embotados de cimento e lágrimas revelam a mistura de argamassa de que é feita tanto a obra quanto o pedreiro, apontando mais uma vez para a dimensão dialética da transformação da natureza pelo homem, ao mesmo tempo em que é transformado por ela através do trabalho (MARX, 1971).

A compreensão do social como constituinte do humano é enfatizada tanto por Vygotsky quanto por Bakhtin, quer seja pelo processo de mediação simbólica quer seja pelo dialogismo da linguagem. “O social está lá, presente, mesmo quando estamos sozinhos; ele não está fora de nós mesmos, nem somente entre nós, ele está em nós, no espírito e no corpo de cada um de nós" (CLOT, 2007, p. 23).

A atividade psicológica é mediada pela linguagem e uso de instrumentos, através da relação entre sujeitos e objetos (sujeito x sujeito x objeto). O processo de humanização não 
é direto, envolve necessariamente uma apropriação do repertório cultural de uma dada sociedade e uma internalização singularizada que evoca uma renovação (VYGOTSKY, 2000).

$\mathrm{O}$ discurso nesse processo configura-se como uma arena do sentido em suas dimensões dialógicas e responsivas, concebendo um texto como um elo, um espaço de abertura que sinaliza a dimensão inconclusa do enunciado o que por sua vez possibilita o fluxo de diálogo entre as diferentes culturas (BAKHTIN, 1999).

A melodia da canção termina acelerada e em ritmo de fuga, dando ênfase ao drama que culmina com a morte do operário. A entonação vai corroborando com a letra da canção como que imitando o despedaçamento do pedreiro com a queda, denunciando um caso de suicídio no trabalho. A canção toda parece uma construção, ao mesmo tempo, que evoca uma desconstrução, apontando para a dimensão dialética e afetiva presente em todo o discurso.

A morte atrapalha o tráfego, o público, o sábado. Mas, ao mesmo tempo, que a morte desorganiza o cotidiano e a própria canção, ela aparece como possibilidade de visibilidade do operário e de imposição de limites ao processo de reificação sofrido pelo pedreiro que é comparado a um pacote flácido, tímido e bêbado. A morte denuncia uma atividade impedida, mas também surge como possibilidade de demarcar uma subjetividade (CLOT, 2010a).

Em pesquisa realizada sobre suicídio e trabalho em metrópoles brasileiras, observou-se que o comportamento auto agressivo pode ser compreendido tanto como uma denúncia contra a violência psicológica sofrida no trabalho quanto como uma saída frente a situações de humilhação e insignificância social. Na cidade de São Paulo foi possível identificar uma relação entre suicídio e trabalho e uma associação inversa do suicídio com desemprego, indicando que a sobrecarga e o sofrimento psíquico podem ser mais nocivos ao trabalhador do que ao desempregado (CECCON; MENEGHEL; TAVARES; LAUTERT, 2014).

A morte traz a dramaticidade do contexto vivido pelo trabalhador, mas, no entanto, por ser a última vez que o pedreiro age, todos os gestos cotidianos e destituídos de significados especiais ganham por sua vez, sentido.

A produção do sentido também é problematizada por Vygotsky e Bakhtin. Os sentidos são "como acontecimentos semânticos particulares constituídos nas relações sociais" a partir dos signos; e os significados representariam uma zona mais estável da palavra dentro 
de um contexto (BARROS, 2012a, p. 138). Bakhtin, em consonância com Vygotsky, concebe significado ligado a sua dimensão abstrata, de dicionário, já o sentido estaria ligado ao contexto, que seria construído mediante as diversas interações de alteridade.

\footnotetext{
A significação não está na palavra nem na alma do falante, assim como não está na alma do interlocutor. Ela é o efeito da interação do locutor e do receptor produzido através do material de um determinado complexo sonoro. É como uma faísca elétrica que só se produz quando há contato de dois polos opostos (BAKHTIN, 2002, p. 132).
}

A significação dada ao operário ao longo de toda a canção é de um estorvo, um incômodo, um empecilho a tudo que está constituído, já posto. Sua morte no sábado atrapalhando o trânsito e o público reforça sua condição de obstáculo (CHAMIE, 2004).

A canção corrobora para demarcar o posicionamento político-social de Chico Buarque de Hollanda que costuma dar voz as minorias marginalizadas, como a do malandro, a prostituta, o pederasta, o pivete, o mendigo e o trabalhador (SILVA, 2004).

A melodia também acompanha esse processo dialógico caracterizado pela tensão e alteridade com a entrada do coral do grupo MPB4 na primeira versão da canção.

Toda a canção é apresentada através dos verbos no passado (amou, beijou, atravessou, subiu, ergueu, sentou, comeu, bebeu, dançou, tropeçou, flutuou, acabou, agonizou e morreu) apontando para uma impossibilidade de retorno, no entanto, a inserção da morte aponta para a possibilidade de uma subversão do status quo e, quiçá, para uma atividade do sujeito trabalhador. "O real da atividade é, igualmente, o que não se faz, o que se tenta fazer sem ser bem sucedido - os fracassos - o que se desejaria ou poderia ter feito e o que se pensa ser capaz de fazer noutro lugar" (CLOT, 2010a, p.103).

O sábado, símbolo do tempo livre, do lazer, aparece como metáfora do descanso. Para o pedreiro é necessário morrer para obter repouso, frente às exigências mecanicistas do capital e da compulsão pelo trabalho que vai sendo construída como único caminho de cidadania e inclusão social.

Todo o poema-canção aponta para a construção de uma queda para a morte, uma trajetória já conhecida frente às condições de trabalho e de segurança precárias. À medida que a canção se desenvolve, vai sendo apresentado o modo de vida, o afetivo, a construção de uma subjetividade assim se faz possível, formada na interface dos processos inter e intrapsicológicos. 


\section{CONSIDERAÇÕES FINAIS}

A articulação entre discurso e trabalho, através da análise concreta de um discurso sobre o trabalho e as aproximações teóricas e epistemológicas apontadas entre Vygotsky e Bakhtin parecem ter composto uma sólida teia de conexões que podem ser aprofundadas a partir deste texto.

A tese dialética de que a subjetividade não pertence ao individuo, mas encontra-se na interface entre os processos intra e interpsíquicos serviu como fio condutor de todo o trabalho, fazendo com que não se recaia na dicotomia social e individual tão nefasta para as Ciências Humanas.

O lugar da subjetividade é enfatizado, a partir das referências apresentadas, como um "entre lugar", sendo a linguagem um amálgama entre interior e exterior (BARROS, 2012a, p.143).

[...] o psiquismo subjetivo localiza-se no limite do organismo e do mundo exterior, vamos dizer, na fronteira dessas duas esferas da realidade. É nessa região limítrofe que se dá o encontro entre o organismo e o mundo exterior, mas este encontro não é físico: o organismo e o mundo encontram-se no signo (BAKHTIN, 2002, p.49).

A partir dessas bases, "a alteridade constitui o sujeito" que é também ativo, construtor e transformador de sua realidade e também produtor de sentidos através da mediação simbólica e da dialogia (COSTA, 2005, p. 375).

A partir da canção "Construção", foi possível observar que uma atividade esvaziada de sentido perde-se em seus objetivos e em potência de ação, portanto, perdendo sua vitalidade. Contudo, a possibilidade da canção servir como uma denúncia ao contexto precário de trabalho vivenciado pelo pedreiro, também pode funcionar como um mobilizador de uma transformação social.

A produção de sentidos favorece a tomada de consciência e amplia o poder de agir sobre a realidade. Esse processo se dá através das conexões entre atividades e na apropriação e internalização das experiências vividas dentro de um contexto histórico-cultural.

O discurso da canção "Construção" é pleno de vivências de sentidos e, portanto, recurso apropriado para a tomada de consciência, integrando dialeticamente o cognitivo e o afetivo, o que pode ser reiterado de forma também dialógica com o trecho de outra canção de Chico Buarque de Hollanda (1966), intitulada "Pedro pedreiro" que segue abaixo: 
Pedro pedreiro penseiro esperando o trem

Manhã parece, carece de esperar também

Para o bem de quem tem bem de quem não tem vintém

Pedro pedreiro fica assim pensando

Pedro pedreiro, bem que poderia ser o protagonista oculto da canção "Construção", compartilhando inclusive de suas condições socioeconômicas, mas Pedro insiste em, além de ser pedreiro, ser penseiro e ter um bem.

O resgate do discurso transpessoal e estilístico, construído no gênero profissional a partir da proposta de Clot, se apresenta como um caminho de possibilidades de ações ainda não realizadas, mas que possivelmente podem favorecer ao processo de tomada de consciência e, quiçá, de consciência de classes.

A partir do vislumbre dessa possibilidade de transformação este artigo é finalizado com as palavras do poeta-cantor Chico Buarque de Hollanda (1966):

\footnotetext{
Pedro pedreiro tá esperando a morte

Ou esperando o dia de voltar pro Norte

Pedro não sabe mas talvez no fundo

Espere alguma coisa mais linda que o mundo.
}

\section{REFERÊNCIAS}

ANTUNES, R. Adeus ao trabalho? ensaio sobre as metamorfoses e a centralidade no mundo do trabalho. São Paulo: Cortez, 2010.

BAKHTIN, M. A cultura popular na idade média e no renascimento: o contexto de Fraçois Rabelais. Trad. M. Lahud \& Y.F. Vieira. São Paulo: Hucitec, 1999.

BAKHTIN, M. Estética da criação verbal. Trad. M. Lahud \& Y.F. Vieira. São Paulo: Martins Fontes, 2000.

BAKHTIN, M. Marxismo e filosofia da linguagem: problemas fundamentais do método sociológico na ciência da linguagem. Trad. M. Lahud \& Y.F. Vieira. São Paulo: Hucitec, 2002.

BARROS, J. P. P. Constituição de "sentidos" e "subjetividades": aproximações entre Vygotsky e Bakhtin. Estudos Contemporâneos da subjetividade - ECOS. São Paulo. V.2 N.1, p.133-146, 2012 a. http://www.uff.br/periodicoshumanas/index.php/ecos/article/view/724 . Acesso em 24 de novembro de 2015.

BARROS, J.P.P. Contribuições de Vigotski e Bakhtin para o conceito de "social" na psicologia. Pesquisas e práticas psicossociais. São João Del Rei,V.7 N.1, p.121 - 129, Janeiro Julho, 2012 b.

Disponível em: 
http://www.ufsj.edu.br/revistalapip/revista_volume_7_numero_1.php. Acesso em: 24 de novembro de 2015.

BORSOI, C. Os sentidos do trabalho na construção civil: o esforço alegre sem a alegria do esforço. In: Vozes (Ed.).In: CODO, W. (Org.). Saúde mental e trabalho: leituras. Petrópolis: Vozes, 2010. p. 309-324.

CECCON, R. F. et al. Suicídio e trabalho em metrópoles brasileiras: um estudo ecológico. Ciência \& Saúde Coletiva, [s.1], v. 19, n. 7, p.2225-2234, jul. 2014. FapUNIFESP (SciELO). http://dx.doi.org/10.1590/1413-81232014197.09722013.

CHAMIE, M. A "práxis" de construção. In: FERNANDES, R. Chico Buarque do Brasil: textos sobre as canções, o teatro e a ficção de artista brasileiro. Rio de Janeiro: Fundação Biblioteca Nacional, 2004.

CLOT, Y. Vygotski: para além da psicologia cognitiva. Trad. Luci Banks Leite. Próposições. V. 17, n. 2, 50, p.19-30, Maio - Agosto, 2006. Disponível em: http://www.proposicoes.fe.unicamp.br/proposicoes/textos/50_dossie_clot_y.pdf. Acesso em 24 de novembro de 2015.

CLOT, Y.A função psicológica do trabalho. Trad. Adail Sobral. Petrópolis: Vozes, 2007.

CLOT, Y. Trabalho e poder de agir. Trad. Guilherme João de Freitas Teixeira e Marlene Machado, Zicca Viana. Belo Horizonte: Artefactum, 2010 a.

CLOT, Y. O diálogo em desenvolvimento: M. Bakhtin no trabalho. In: PAULA, L.; STAFUZZA, G. O. Circulo de Bakhtin: diálogos in possíveis. São Paulo: Mercado de Letras, v.2, 2010b.

COSTA, N. B. Práticas discursivas: exercícios analíticos. Campinas: Pontes, 2005.

COSTA, N.B. Um artista brasileiro: paratopias buarqueanas. In: FERNANDES, R. Chico Buarque do Brasil: textos sobre as canções, o teatro e a ficção de um artista brasileiro. Rio de Janeiro: Biblioteca Nacional, 2004. p. 34-43.

COSTA, N.B. O objeto e o sujeito na pesquisa da canção: uma reflexão bakhtiniana sobre a análise do discurso literomusical. In: COSTA, N.B. (Org.). O charme dessa nação: música popular, discurso e sociedade brasileira. Fortaleza: Expressão gráfica e editora, 2007. p. 1725.

DEJOURS, C. A banalização da injustiça social. Trad. Luiz Alberto Bonjardim. Rio de Janeiro: Fundação Getúlio Vargas editora, 2006.

DRUCK, G. Unrestrained outsourcing in Brazil: more precarization and health risks for workers. Cadernos de Saúde Pública, Rio de Janeiro [s.1.], v. 32, n. 6, p.1-9, 2016. FapUNIFESP (SciELO). http://dx.doi.org/10.1590/0102-311x00146315.

ENGELS, F. Sobre o papel do trabalho na transformação do macaco em homem (1876). Trad. José Américo, 2005 http://forumeja.org.br/sites/forumeja.org.br/files/F_ANGELS.pdf. Acesso em 28 de fevereiro de 2017. 
FERNANDES, R. Cronologia. In: FERNANDES, R. Chico Buarque do Brasil: textos sobre as canções, o teatro e a ficção de um artista brasileiro. Rio de Janeiro: Biblioteca Nacional, 2004. p.25-33.

HOllandA, C. B. Pedro Pedreiro. In: BUARQue, C. Chico Buarque de Hollanda. [Vinil]. Rio de Janeiro: RGE 1966.

HOLlANDA, C.B. Construção. In: BUARQUE, C. Construção. [Vinil]. Rio de Janeiro: Phonogram Philips 1971.

KOGAWA, J. M. M. O discurso-arte de Chico Buarque: poder sobre o sujeito brasileiro. Revista Uruguaiana - Revista acadêmica multidisciplinar. Paraná: Universidade Estadual de Maringá, p. 1-11, 2007.

LIMA, M. E. A. Contribuições da clínica da atividade para o campo da segurança no trabalho. Revista brasileira de saúde ocupacional. São Paulo. 32 (115), p. 99-107, 2007. Disponível em: http://www.scielo.br/pdf/rbso/v32n115/09.pdf. Acesso em 24 de novembro de 2015.

MARX, K. O capital. Rio de janeiro, civilização brasiliense, 1971. vol 02.

SILVA, A. V. O protesto na canção de Chico Buarque. In: FERNANDES, R. Chico Buarque do Brasil: textos sobre as canções, o teatro e a ficção de um artista brasileiro. Rio de Janeiro: Biblioteca Nacional, 2004.

VIGOTSKY, L.S. Teoria e método em Psicologia. Trad. Claudia Berlinet. São Paulo: Martins Fontes, 1996.

VIGOTSKY, L. S. Pensamento e linguagem. Trad. Jefferson Luiz Camargo. 2. São Paulo: Martins Fontes, 2000.

VIGOTSKY, L.S. A formação social da mente: o desenvolvimento dos processos psicológicos superiores. Trad. José Cipolla Neto. São Paulo: Martins Fontes, 2007. 